\title{
Insights from Participatory Prospective Analysis (PPA) workshops in Nepal
}

\author{
Mani Ram Banjade', Naya S Paudel${ }^{2}$ and Esther Mwangi
}

\section{Key messages}

- As Nepal goes through a process of creating a new decentralized federal system of government, a CIFOR-ForestAction project used Participatory Prospective Analysis - a foresight method for co-elaborating future scenarios and developing strategies - to understand emerging issues and to bring the issues and scenarios to forest policy making at the provincial and federal levels.

- Forestry experts identified several external factors likely to impact the rights of community forest user groups under the new federal structure. These factors include national legal frameworks, macroeconomic policies, the emergence of new sub-national governments, and a changing political context. Experts also considered how the future of community forestry might be influenced by internal factors, such as the rules of community forest user groups, governance arrangements, strategies, plan implementation, conflict management systems, and relationships with local governments.

- To strengthen the rights of community forest user groups, experts recommended the following: the adoption of good governance principles in community forest user groups; networking and capacity building; a strengthening of relationships with local government and other stakeholders; the use of improved technology; forest-based enterprise development; and poverty reduction.

- Participatory Prospective Analysis was found to be a good methodological tool for effective planning, and participants thought it could improve local environmental planning. With some customization and contextual refinement, it can be adopted by community forestry groups, local government ward offices and municipalities to assist Nepal's forestry sector in its transition to a decentralized system.

\section{Background}

Introduced in the early 1990s in response to serious environmental degradation, Nepal's community forestry program has become the country's most successful forest tenure reform initiative, hailed internationally for its contribution to biodiversity conservation and climate change mitigation efforts. Almost $40 \%$ of Nepal's population has been involved in managing a third of national forests through more than 22,000 locally formed forest user groups (DOFSC 2018).

However, Nepal has experienced considerable social and political conflict during most of this period. With the absence of local governments for almost two decades (1996-2016), community forestry institutions have been the only functioning rural bodies to sustain grassroots democracy, to offer vital social services and community infrastructure, and

1 ForestAction Nepal and NIMS College, Kanibahal, Lagankhel, Lalitpur, Nepal.Email: mrbanjade@gmail.com

2 ForestAction Nepal, Bagdol, Lalitpur, Nepal to support livelihood activities. Recently, Nepal emerged from this protracted conflict, adopted a federal political structure and has established stable governments at federal, provincial and local levels. Under its new constitution, provincial and local governments enjoy substantial power, particularly in development activities, service provisioning and natural resource management. Now, the key concern of forest user groups is whether their existing rights will be secured under federalism in Nepal. The newly emerged provincial governments and local municipalities will have greater authority and responsibility in community forestry than under the highly centralized system of former times. However, the details of their roles, and what services they will offer to forest user groups, are still evolving. Although there is considerable optimism regarding the ability of communities and local governments to cooperate and collaborate, there are also fears of power struggles that could reduce the role of community forest governance. Likewise, most of the debate on forest governance under federalism has taken place at a national level, with limited feedback from provincial and municipal actors. 
Against this background, CIFOR and ForestAction aimed to better understand emerging issues at the grassroots level, to include them in provincial and national forest policy making, and to introduce Participatory Prospective Analysis (PPA) as a process for collaborative environmental planning at a local level. The team held workshops in Nepal's hill and Terai districts before bringing analysis and insights to stakeholders at the municipal, provincial and national levels.

This collaborative project formed part of a series of research and engagement activities under the CIFORled Global Comparative Study on Forest Tenure Reform (GCS Tenure, www.cifor.org/gcs-tenure). The aim is to improve understanding, communication and stakeholder engagement in developing countries in order to support stronger tenure security, livelihoods and sustainable forest management.

This infobrief summarizes the PPA process and provides key insights from four PPA workshops held in two municipalities in Nepal. The next section provides a brief outline of the PPA process. This is followed by a summary of the workshops, which are compared and contrasted across the two sites. The final section reflects on the workshop outcomes.

\section{Participatory Prospective Analysis}

PPA is a planning tool that aims to anticipate plausible scenarios in the future. Its foresight approach explores future alternatives by developing different visions and their associated key components (or drivers). The PPA process identifies relevant stakeholders and recognizes them as experts. The exploration of future options is then used to conduct exercises for planning strategies and actions in pursuit of an ideal future selected by the collective.

PPA was implemented in a series of workshops in Nepal and was instrumental in developing a shared understanding among stakeholders with regard to many dimensions of forest tenure reform as well as factors affecting tenure security. Discussion about the drivers of change is key to building a better future while being cognizant of the other possible future scenarios (Bourgeois et al. 2017).

The PPA process involves working through these six sequential steps (see Figure 1). These steps are described in more detail in Box 1.

In Nepal, facilitator training was organized in November 2016, attended by 23 professionals and practitioners

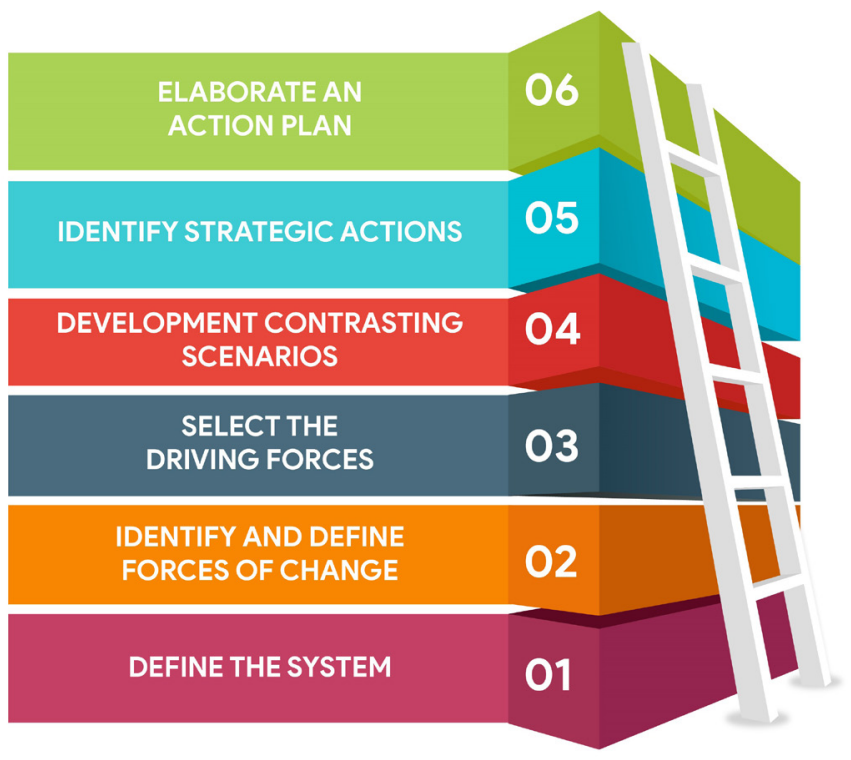

Figure 1. Sequential steps of PPA implementation

representing the government forestry service, NGOs, academic institutions and forestry networks. PPA workshops were then implemented in Buddhabhumi municipality (Kapilvastu district) and Chautara Sangachowkgadhi municipality (Sindhupalchowk district) (see Figure 2) to represent the regions of Terai and the hills respectively. Terai and the hills were chosen due to their significant differences in the productive potential of forests; the value of forest products; the socio-economic complexities; and the role of actors in forest governance. Experts attending the workshops - held in June and July 2018 - included leaders of selected forest user groups, representatives from local municipalities, the government forest service, NGOs and forest-based entrepreneurs.

The PPA workshops followed the same format in both locations. After PPA implementation workshops, a meeting was held at the municipality level in each district, followed by state-level meetings, to inform stakeholders and to solicit feedback.

\section{Key outcomes}

\section{Defining the forces of change}

Participants were asked to discuss their potential hopes and fears for the coming decades in relation to community forestry rights. Local stakeholders expressed fears that forest user groups might eventually lose their rights and autonomy under federalism, due to conflicting regulatory provisions and corresponding stakeholder claims. There 


\section{Box 1. Key steps for PPA implementation (see Bourgeois et al. 2017 for detailed guidelines)}

\section{Defining the system}

The first step in the process is to clarify these four questions: what, where, how long and who (which collectively define the system). The main 'what' question used to define the system is: What could be the future scenarios for forest tenure security? The 'where' question leads to defining a geographical territory. In the case of PPA implementation in Nepal, the territory covered multiple community forest user groups within a specified municipality. 'How long' defines the time period considered for the future scenarios; in our cases, stakeholders defined a 10-year time frame. 'Who' means identifying relevant stakeholders, whose stakes are linked with the future of forest tenure security.

\section{Identifying and defining forces of change}

The second step in the PPA process is to list forces of change, which have the capacity to significantly transform the system in the future. To identify these forces, the stakeholders were asked to discuss their greatest fears and hopes for the future of forest tenure security in their area over the next 10 years. The factors that potentially trigger a change toward a hope or fear are known as forces of change. These forces could be external or internal to the system. The external forces are beyond the capacity of local stakeholders to influence them, so the defining driving forces and scenario building are largely based on the internal forces.

\section{Selecting driving forces}

Once the list of the internal forces is finalized and each force is defined, interrelationships among these forces are discussed. The interrelationship is defined by evaluating the direct influence of each force on the others (i.e. whether Force A has a direct influence on Force $B$ and vice versa). A value of 1 is given when there is direct influence, otherwise a value of 0 is given. This binary evaluation is then used to analyze the influence and dependence of each force by using structural analysis software. The value generated for each force in terms of influence and dependence is then plotted on a graph. The forces with low influence and low dependence are called 'outliers'; forces with low influence and high dependence are called 'outputs'; forces with high influence and high dependence are called 'leverages'; and forces with high influence and low dependence are called 'drivers.' These driving forces are then used in developing the scenarios.

\section{Building future scenarios}

A future scenario is an anticipated plausible state in the future of forest tenure security and is produced by combining the coherent states of the driving forces. Hence, the first step to building a future scenario was to identify different contrasting states that a driving force could have in the future. For example, for the driving force 'the rules of user group,' see the example of the contrasting states identified by the participants:

\begin{tabular}{|c|c|c|c|c|c|c|}
\hline \multirow[t]{2}{*}{ Driving force } & \multicolumn{6}{|c|}{ Different states of the driving force } \\
\hline & 1 & 2 & 3 & 4 & 5 & 6 \\
\hline $\begin{array}{l}\text { A. Rules of user } \\
\text { group }\end{array}$ & $\begin{array}{l}\text { Pro-poor } \\
\text { Inclusive, } \\
\text { democratic } \\
\text { and powerful; } \\
\text { sustainable forest } \\
\text { management; pro- } \\
\text { poor livelihood- } \\
\text { focused provision }\end{array}$ & $\begin{array}{l}\text { Dominating } \\
\text { (Haikamvadi) } \\
\text { Self-centered, rich } \\
\text { focus; autocracy } \\
\text { of leadership; } \\
\text { no forest } \\
\text { management } \\
\text { system }\end{array}$ & $\begin{array}{l}\text { Surrender } \\
\text { Policies entirely } \\
\text { dictated by } \\
\text { external forces }\end{array}$ & $\begin{array}{l}\text { Corporatism } \\
\text { (Thekedarmukhi) }\end{array}$ & $\begin{array}{l}\text { Land use } \\
\text { change } \\
\text { Polices of } \\
\text { converting forest } \\
\text { land to other } \\
\text { land uses }\end{array}$ & $\begin{array}{l}\text { Anarchism } \\
\text { No more } \\
\text { rules and } \\
\text { regulations }\end{array}$ \\
\hline
\end{tabular}

Once different states were agreed upon for each driving force, the next step was to identify the combination of states that cannot co-exist. While developing scenarios, those incompatible states were discarded. Each scenario was then developed by combining one particular state for each driving force. The multiple scenarios were therefore constructed with a combination of different states of the driving forces. The next step was to develop a narrative for each scenario - e.g. how this would evolve over the selected timeline. The participants then selected the most desirable and undesirable scenarios before working on the action plans.

\section{Action plan}

Different community forest user groups (CFUGs) and local government representatives were present in the workshops and had agreed to work in their respective institutions on a pathway from scenarios to action. Together, however, they developed a list of common strategies that they should apply across institutions in order to make the desirable scenario a reality. 


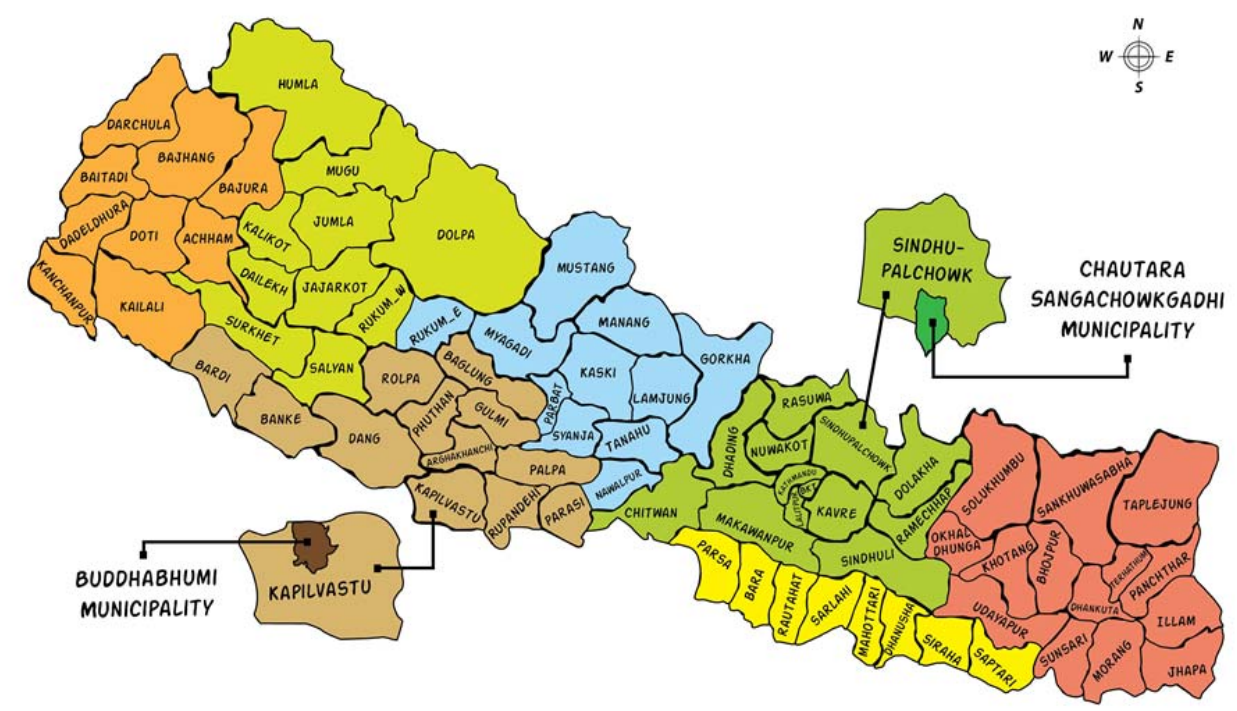

Figure 2. Map of municipalities where PPA activities were conducted

were also fears that local governments may start levying more taxes, and that partisan politics could jeopardize the success of community forestry. On the other hand, stakeholders were also hopeful that local government services would be provided faster, access to services would be easier, tenure security would be stronger, and collaboration with local governments would be simpler and more effective. These reflections were used to identify potential forces of change, many of which were related to the national legal frameworks, macroeconomic policies and changing political context. In order to focus on the aspects that they were able to influence, participants created a list of internal forces.

These were largely the same across the two municipalities, with both identifying the following key internal factors as especially relevant: forest management technology; working strategy; plan implementation; community forestry's contribution to community development; benefit sharing/ distribution; information and communication; user group governance system; relationships between stakeholders; forest condition; condition of forest enterprises; user group rules; transparency; allocation of rights and responsibilities; conflict management system; awareness levels; and participation.

Chautara Sangachowkgadhi municipality identified a few additional forces of change, such as user group leadership; inclusion in community forestry; condition of physical infrastructures; and the contribution of local government representatives. Buddhabhumi municipality stakeholders additionally identified the relationship between local government and community forest user groups; attitude; self-motivation; sources of motivation; types of rights; the relationship between rules and regulations; and financial management.
Overall, the forces that the experts identified as most relevant can be summarized in terms of extent and security of rights obtained; group governance; relationships with other actors; behavioral aspects; the condition of forest resources and infrastructure; technology; and the market.

\section{Unveiling the driving forces}

The next step was to assess the interdependence between the forces of change and to identify five or six driving forces based on their influence on other factors. After finalizing 20-23 forces of change, data were entered in the PPA structural analysis software, which revealed the direct and indirect influence, dependence, strength and weighted strength. Using a combination of direct and indirect influence and dependence, this software highlighted the status of each force of change in terms of its influence and dependence on other forces.

Five forces of change were identified in both municipalities as key driving forces (see Figure 3): user group rules; user group governance system; working strategy; conflict management system; and plan implementation. Buddhabhumi municipality also identified relationships between local government and community forest user groups as key driving forces.

In the following stage of developing scenarios and strategies, those forces that lie in the 'leverages' quadrant (e.g. participation, attitude, level of awareness and information and communication) are key to improving the effectiveness and efficiency of driving forces, while 'outputs' forces should benefit from interventions. 


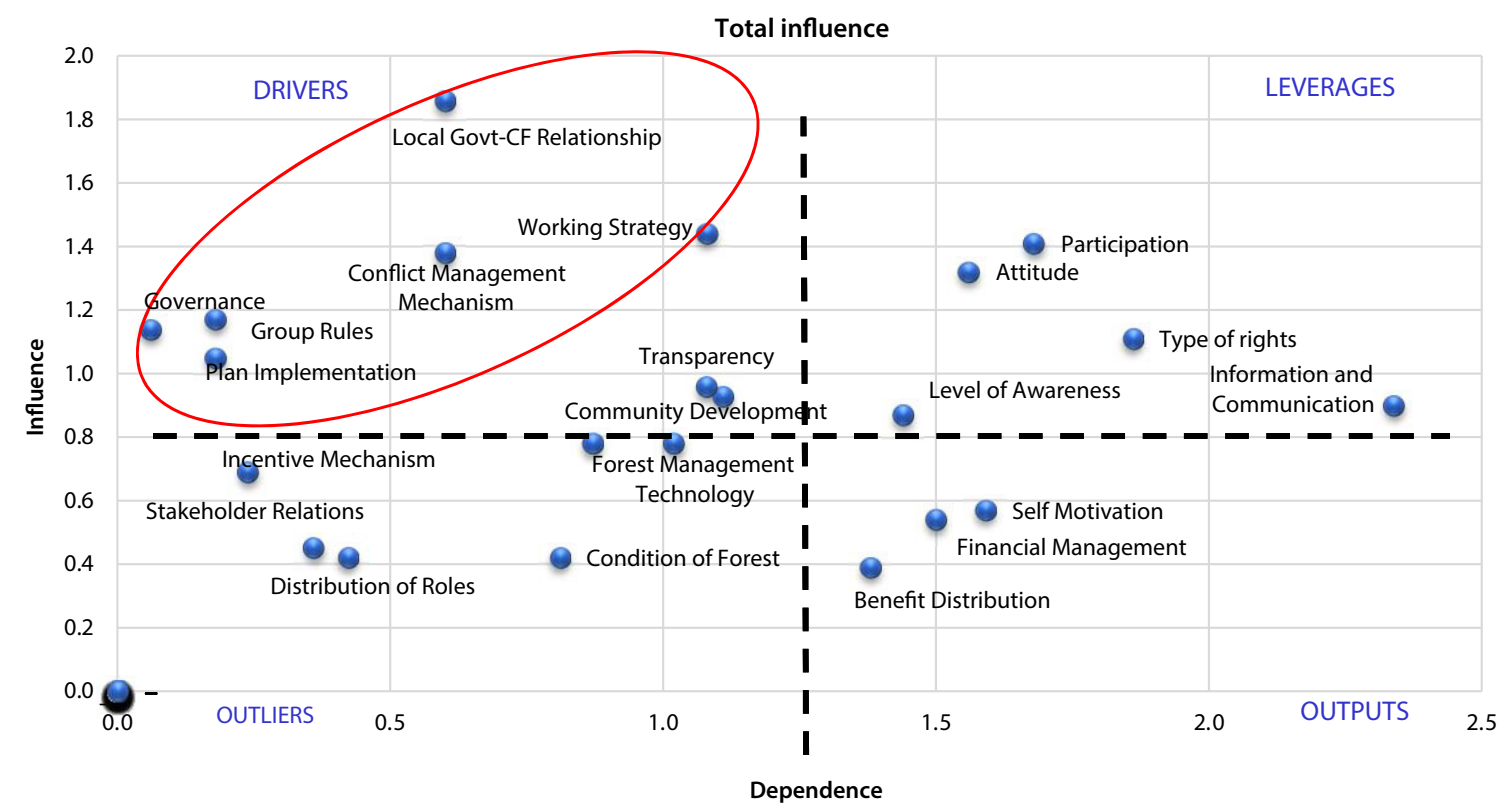

Figure 3. Graph of total influence and dependence of forces of change identified in Buddhabhumi (The graph is automatically generated by the structural analysis software. Two lines in the graph indicate the average influence and dependence. As indicated in the graph, the average influence is 0.8 and average dependence is 1.2.)

\section{From driving forces to future scenarios}

A scenario is a description of how the future may unfold according to an explicit, coherent and internally consistent set of assumptions about key relationships between driving forces. Future scenarios of community rights over forests under federalism were constructed with the premise that it was possible to foresee plausible futures based on the different potential states of the driving forces. Experts worked to identify all possible scenarios based on all plausible combinations of the driving forces' states. Once there was agreement on scenarios considered to be sufficiently contrasting and diverse enough to explore, each scenario required a more complete description (i.e. a narrative). Experts developed scenario narratives based on the combination of diverse states of the driving forces, while also thinking about the influence of other forces of change. Examples of the most and least desirable scenarios are presented here (see boxes 2 and 3 respectively).

\section{Developing strategies}

Facilitators helped experts to identify strategies that support desirable scenarios and avoid undesirable ones. In total, participants finalized 15 strategies for Buddhabhumi municipality of Kapilvastu district (K) as well as 17 strategies for Chautara Sangachowkgadhi municipality of Sindhupalchowk district (S) to strengthen the rights of community forest users in federal Nepal.

\section{Box 2. Most desirable scenario: Our prosperous community forest}

In 2028, all of Chautara Sangachowkgadhi municipality's forest is very active and almost all community forest user groups have implemented a sustainable forest management system. The governance system has been enhanced with proper transparency and accountability. Inclusive democracy and collective action are institutionalized in community forest. Coordination, co-existence and cooperation are developed across the municipality, district forest office and all other stakeholders. A strategic plan for integrated resource management has been prepared in a participatory way, and communities are actively implementing these plans while taking full ownership. The use of advanced technology in forest management and enterprise development has been contributing to the community development and livelihood improvement of forestdependent poor people. A remarkable contribution has been made to the local and national economy, while the condition and availability of forest, biodiversity and ecosystem services have been sufficiently improved.

Inclusive and integrated planning: Experts in both locations will adopt strategies for an inclusive, informed, integrated and nested planning process. This will include the poor, women, Dalits and other forest-dependent groups; 


\section{Box 3. Least desirable scenario: Unmanaged community forest}

In 2028, Chautara Sangachowkgadhi municipality's forests are unmanaged and haphazard. Problems such as deforestation, environmental degradation, forest fires and shortages of forest products are increasing. Forest user groups are largely inactive and hardly holding any meetings or discussions. Users are threatened if any complaints are made regarding committee activities. Most of the decisions are made by very few elites, and all the benefits are also taken by elites. Similarly, the contribution of forests to the livelihoods of forest-dependent poor, women and marginalized groups is very limited. There is no participation in the activities of the user group. Illegal forest activities are increasing. Community forests do not cooperate with the municipality and the ward office, so conflicts are increasing in the forest. The forest is in poor condition. The government is almost at the stage of taking back the community forest.

integrate forest management plans with community development plans and other sectoral plans; and maintain the coherence of plans between community forest user groups and local governments. Nested planning will integrate community forestry plans with those of local governments.

Adopting principles of good governance: Experts in both places placed an emphasis on applying good governance principles to community forest user groups. This includes securing representation and participation of marginalized groups in the executive committee and other decision-making bodies; ensuring accountability and responsiveness; maintaining transparency; improving communication and information exchange; and developing an appropriate mechanism for conflict management. Forming a rapid response team was also suggested for increased responsiveness of authorities (S).

Networking and capacity building: Experts recommended institutionalizing a community forest user group forum at municipality level to secure and extend the rights of communities over forests, while effectively facilitating technical support and market access (K). This forum could also share learning among user groups, and help them develop consistent policies (K). The need for institutional capacity building was also highlighted, particularly on forest management, account keeping, leadership development and conflict transformation (K).

\section{Strengthening relationships with local government and} other stakeholders: Experts recommended that municipal regulations and programs related to forestry and the environment be formulated through appropriate consultation and cooperation with user groups (K). The municipality should also provide technical, institutional and other services to community forestry, and prioritize community forestry in annual planning and budgeting. Strong relationships with other actors - e.g. the ward office, municipality, district forest office and the Federation of Community Forestry Users Nepal (FECOFUN) - were also highlighted for effective plan development and execution (S).

Use of improved technology: A major strategy was related to the use of advanced technology for the effective management of community forestry (S). The aim was to increase productivity by applying appropriate silvicultural techniques, and to promote ecosystem services. This strategy would run alongside an appropriate incentive (K) and appropriate punishment mechanism to enforce rules and curb deforestation (S).

Entrepreneurship development: Strategies also involved enterprise development; this would increase income generation and employment opportunities through forest enterprises, while exploiting market opportunities through better organization and transparency in the trade of timber and other forest products (K). User groups should prioritize employment generation through forest-based entrepreneurship (i.e. sawmills, timber- and fruit-based enterprises, and through promoting ecotourism) (S).

Livelihoods and poverty reduction initiatives: As existing poverty reduction initiatives by community forestry are ineffective, special programs will be prioritized for forestdependent poor (K). Similarly, an equity-oriented forest product distribution system will be implemented (S) with a focus on poverty reduction.

\section{Developing an action plan}

All community forest user groups in attendance agreed to develop an action plan for their own community forest in order to achieve the desired scenario. User group representatives made written commitments for action plan development with the help of leaders from FECOFUN, the district forest office and local government. 


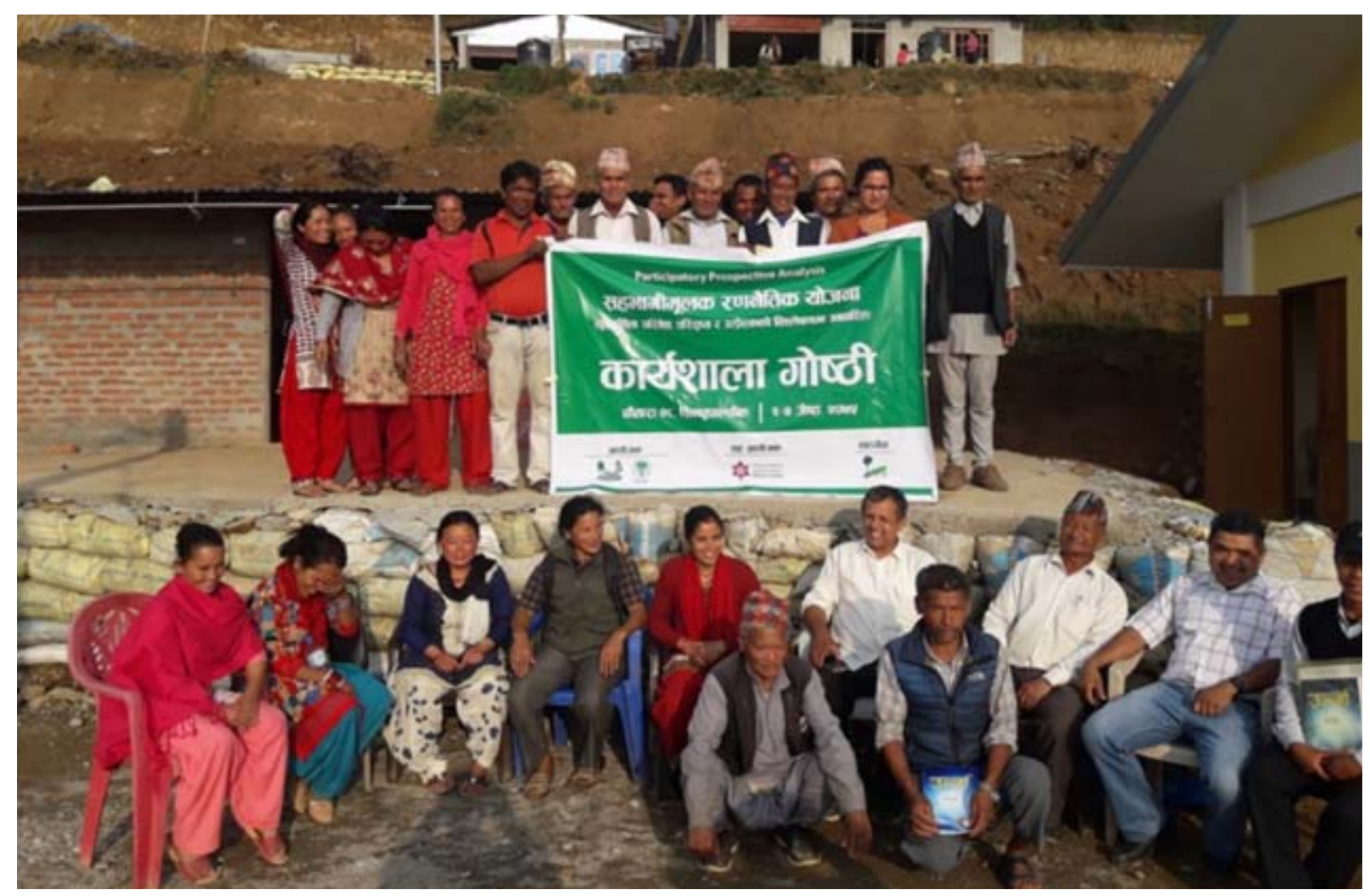

Figure 4. Participants at the PPA workshop in Nepal.

\section{Conclusions}

Based on two training programs and municipality-level workshops, participants thought that PPA was a useful methodological tool for effective planning, and that its robust design and integrated approach would have long-lasting effects on community forestry in the region. As one user group representative from Buddhabhumi expressed, "The scenarios, particularly the most desirable scenario, provided us with a vision, and strategies that we have developed are equally applicable to all of our community forest user groups... the complete list provides us with a framework, which we can use as a benchmark for strengthening community rights, improving governance and reducing poverty."

With some customization and contextual refinement, PPA can be adopted as a planning tool by community forestry groups, local government ward offices and at the municipality level. ForestAction is now adopting the PPA approach in another project to facilitate collaborative planning between local governments and community forest user groups across five project sites in two districts.
Some considerations were highlighted for future adoption of PPA in Nepal. Participants emphasized that the nature and technicalities of the training required educated, literate, well-informed and committed forestry leaders who were able to attend both workshops for continuity. It was likewise considered important to have experienced facilitators, including female facilitators, who can internalize the concepts and rationale of PPA while possessing some knowledge and skills in running computer software. The time availability of local leaders must also be considered; these workshops were condensed from the currently practiced six-day session.

\section{Acknowledgements}

This document has been published in collaboration with ForestAction. CIFOR's "Global Comparative Study on Forest Tenure Reform" is funded by the European Commission and the Global Environmental Facility (GEF) with technical support from the International Fund for Agricultural Development (IFAD) and the United Nations Organization for Food and Agriculture (FAO). We thank Robin Bourgeois for training the team of facilitators in 
PPA methodology and express our appreciation to FAO and Steve Lawry for their comments on a previous draft of this infobrief. We are also grateful to Buddhabhumi and Chautara Sangachowkgadhi municipality stakeholders who contributed to the PPA process. This study forms part of the Program on Policies, Institutions and Markets (PIM), led by the International Food Policy Research Institute (IFPRI); and the CGIAR Research Program on Forest, Trees and Agroforestry (FTA), led by CIFOR. The opinions expressed in this infobrief represent the analysis of the authors and do not necessarily reflect the views of IFPRI, CIFOR, CGIAR or the financial sponsors.

\section{References}

Bourgeois R, Liswanti N, Mukasa C, Zamora A, Herawati T, Monterroso I, Mshale B, Banjade MR, Mwangi E and Larson A. 2017. Guide for co-elaboration of scenarios: Building shared understanding and joint action for reform and security of forest tenure. CIFOR: Bogor, Indonesia.

DOFSC 2018. CFUG Database. Kathmandu, Nepal:

Department of Forests and Soil Conservation. Accessed

1 November 2019. http://dof.gov.np/image/data/ Community\%20Forestry/CF\%20Data\%20Update\%20 2075_02_04.pdf

\begin{tabular}{|c|c|c|}
\hline$\underbrace{\text { by }}_{\text {CGIAR }}$ & $\begin{array}{l}\text { RESEARCH } \\
\text { PROGRAM ON } \\
\text { Policies, } \\
\text { Institutions, } \\
\text { and Markets } \\
\quad \text { Led byIFPRI }\end{array}$ & $\begin{array}{l}\text { The CGIAR Research Program on Policies, Institutions, and Markets (PIM) leads action-oriented research } \\
\text { to equip decisionmakers with the evidence required to develop food and agricultural policies that better } \\
\text { serve the interests of poor producers and consumers, both men and women. PIM combines the resources } \\
\text { of CGIAR centers and numerous international, regional, and national partners. The program is led by the } \\
\text { International Food Policy Research Institute (IFPRI). www.pim.cgiar.org }\end{array}$ \\
\hline
\end{tabular}

\begin{tabular}{|l|l|l|l|l} 
& This research was carried out by CIFOR as part of the CGIAR Research Program on Forests, Trees \\
and Agroforestry (FTA). FTA is the world's largest research for development program to enhance \\
the role of forests, trees and agroforestry in sustainable development and food security and \\
to address climate change. CIFOR leads FTA in partnership with Bioversity International, CATIE, \\
CIRAD, INBAR, ICRAF and TBI. \\
FTA's work is supported by the CGIAR Trust Fund: cgiar.org/funders/
\end{tabular}

\section{JIFAD}

gef Enabling poor rural people

Enabling poor rural peop
to overcome poverty partners' capacity, and actively engaging in dialogue with all stakeholders to inform policies and practices that affect forests and people. CIFOR is a CGIAR Research Center, and leads the CGIAR Research Program on Forests, Trees and Agroforestry (FTA). Our headquarters are in Bogor, Indonesia, with offices in Nairobi, Kenya; Yaounde, Cameroon; Lima, Peru and Bonn, Germany. 